Plant Tissue Cult. \& Biotech. 22(2): 137-142, 2012 (December)

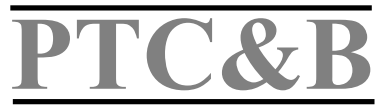

\title{
Efficient in vitro Regeneration of a Medicinal Plant Harsinghar (Nyctanthes arbor-tristis L.)
}

\author{
S. Bansal, A.J. Bharati ${ }^{1}$ and Y.K. Bansal ${ }^{1 *}$ \\ Department of Botany, Hitkarini Mahila Mahavidyalaya Jonsganj, Jabalpur-482002 \\ (M.P.), India
}

Key words: In vitro propagation, Nyctanthes arbor-tristis, Axillary bud, Multiple shoot

\begin{abstract}
In vitro propagation of Nyctanthes arbor-tristis L. has been successfully established from axillary bud explants on MS. Maximum number of multiple shoots was obtained on MS containing BAP $(22.2 \mu \mathrm{M})$. Half strength of MS (2\% sucrose) supplemented with NAA $(10.74 \mu \mathrm{M})$ provided the maximum frequency of root initiation. The plantlets were successfully hardened.
\end{abstract}

\section{Introduction}

Medicinal plants are the natural and safer source of phytochemicals to fight against new strains of a microorganism. Currently, a great deal of public interest is witnessed in the use of herbal remedies; furthermore many western drugs had their origin in plant extract (Arulmozhi and Sathiya 2007). Due to rapid destruction of habitat the natural populations of a number of medicinal plants have been reduced considerably and several have become extinct. Among the different approaches, their in vitro culture provides new means of conserving and rapid propagation of valuable, rare and endangered medicinal plants (Karuppusamy and Pullaiah 2007).

Nyctanthes arbor-tristis L. (Oleaceae), commonly known as 'Harsinghar' is a valuable medicinal plant, and grows in Indo-Malayan region. It is cultivated in gardens almost throughout India (Nair and Mahanan 2001). Different parts of this plant species are known to cure various ailments (Vats et al. 2009). Flowers are used as stomachic, carminative, astringent for bowel, antibilious, expectorant, hair tonic and in the treatment of piles, skin diseases, etc. (Khatune et al. 2003).

*Author for correspondence. ${ }^{1}$ Plant Tissue Culture Laboratory, Department of Bioscience, R. D. University, Jabalpur (M.P.)-482001, India. <yogendrakbansal@rediffmail.com>. 
Powdered Stem bark is used to treat rheumatic joint pain, malaria (Suresh et al. 2010), and bronchitis (Kirtikar and Basu 1993). Leaves are used as a laxative, diaphoretic, diuretic (Tuntiwachwuttiku et al. 2003), and against high blood pressure and diabetes (Nawaz et al. 2009). Seeds are used as anthelmintic and for treating alopecia and bilious fevers (Nair et al. 2005), affections of scalp, piles and skin disease (Sasmal et al. 2007). Leaves contain $\beta$-amyrin, $\beta$-sitosterol, benzoic acid, nyctanthic acid (Talakal et al. 2000). Seeds contain fixed oil having glucosides of linoleic, oleic, stearic, palmitic acid and $\beta$-sitosterol.

Due to poor seed germination on account of the presence of phenolic compounds and alkaloids in the pericarp and seed coat (Bhattacharya et al. 1999), many young seedlings die under natural conditions (Anon. 1988). The present study therefore aims at developing an efficient protocol for in vitro propagation of this medicinally important plant Nyctanthes arbor-tristis.

\section{Materials and Methods}

Healthy plants of Nyctanthes arbor-tristis L. were collected from the nursery of Jawaharlal Nehru Krishi Vishwavidyalaya, Jabalpur. Axillary buds were excised into $0.5-0.7 \mathrm{~cm}$ and washed under running tap water to remove soil and other superficial contamination.

To minimize contamination caused by fungus, endogenous and exogenous bacteria, explants were surface sterilized for $2 \mathrm{~min}$ in $70 \%(\mathrm{v} / \mathrm{v})$ ethanol and surface disinfected with an aqueous solution of $0.1 \% \mathrm{HgCl}_{2}$ for $3 \mathrm{~min}$. The disinfectant was removed by rinsing the material with sterilized distilled water five to six times. The explants were then dried on sterile filter paper, sectioned and aseptically inoculated to the medium.

The culture media consisted of MS basal constituents supplemented with different concentration BAP and $\mathrm{Kn}$. The media were supplemented with 3\% sucrose and $0.8 \%$ agar was used as the gelling agent. The $\mathrm{pH}$ of the media was adjusted between $5.6-5.9$ by $0.1 \mathrm{~N} \mathrm{NaOH}$ and autoclaved at $121^{\circ} \mathrm{C}, 15 \mathrm{lb}$ pressure for $45 \mathrm{~min}$. The cultures were maintained at $25 \pm 2^{\circ} \mathrm{C}, 16 / 8 \mathrm{hr}$ (light/dark) photoperiod with a light intensity of 1500 lux at relative humidity (RH) of $60-70 \%$. For root induction in vitro grown 8 weeks old micro-shoots were transferred to half strength of MS with $2 \%$ sucrose devoid of agar supplemented with different concentrations of IBA, NAA and IAA, respectively. Plantlets with well grown roots were removed from the culture tubes; dipped in $1 \%$ bavistin solution, washed in tap water and then transferred to poly cups containing sterilized soil: sand: farmyard manure $(1: 1: 1)$. The regenerants were hardened for four weeks, by covering the cups with a thin perforated transparent 
polythene bag to maintain humidity and were watered with distilled water for first week then with tap water.

\section{Results and Discussion}

The effect of cytokinins and auxins on morphogenesis of axillary bud explants are presented in Tables 1 and 2. Emergence of multiple shoot buds from axillary explants on MS supplemented with BAP was observed. Nodal explants were found to be the best source of multiple shoot induction. A number of authors have also suggested the same type of explants for propagation of other medicinal plants, such as Rouwolfia serpentina (Roy et al. 1995), Emblica officinalis (Rahaman et al. 1999), Holarrhena antidysenterica (Ahmed et al. 2001) and Enicostemma hyssopifolium (Seetharam et al. 2002).

Table 1. The effect of PGRs on regeneration from axillary buds of $N$. arbor-tristis (Values are Mean $\pm S E$ ).

\begin{tabular}{llllllc}
\hline Sl.No & PGR & Conc. $(\mu \mathrm{M})$ & FSI $(\%)$ & MSN & MSL $(\mathrm{cm})$ & MNN \\
\hline 1. & Control & 0 & 52.77 & $1.66 \pm 0.130$ & $0.81 \pm 0.080$ & - \\
2. & BAP & 0.44 & 84.37 & $2.86 \pm 0.294$ & $2.41 \pm 0.169$ & $1.86 \pm 0.191$ \\
3. & & 2.22 & 81.25 & $4.26 \pm 0.407$ & $4.18 \pm 0.321$ & $2.6 \pm 0.235$ \\
4. & & 4.44 & 75.00 & $7.13 \pm 0.653$ & $3.26 \pm 0.306$ & $2.2 \pm 0.200$ \\
5. & & 6.66 & $\mathbf{9 3 . 7 5}$ & $8.53 \pm 1.004$ & $2.82 \pm 0.174$ & $2.13 \pm 0.273$ \\
6. & & 17.76 & 84.35 & $13.46 \pm 0.950$ & $0.91 \pm 0.086$ & $1.33 \pm 0.125$ \\
7. & & 22.2 & 90.62 & $\mathbf{1 4 . 1 3} \pm 0.999$ & $0.813 \pm 0.072$ & $1.20 \pm 0.118$ \\
8. & Kn & 0.46 & 71.87 & $1.8 \pm 0.144$ & $2.90 \pm 0.219$ & $2.53 \pm 0.153$ \\
9. & & 2.32 & 43.7 & $2.33 \pm 0.270$ & $3.05 \pm 0.210$ & $2.6 \pm 0.190$ \\
10. & & 4.64 & 43.9 & $4.26 \pm 0.383$ & $3.63 \pm 0.220$ & $2.73 \pm 0.228$ \\
11. & & 6.96 & 46.87 & $3.4 \pm 0.305$ & $4.87 \pm 0.276$ & $4.13 \pm 0.169$ \\
12. & & 9.28 & 71.86 & $2.06 \pm 0.236$ & $4.04 \pm 0.225$ & $3.13 \pm 0.191$ \\
13. & & 23.2 & 53.12 & $1.73 \pm 0.210$ & $2.20 \pm 0.322$ & $1.93 \pm 0.266$ \\
\hline
\end{tabular}

FSI $=$ Frequency of shoot initiation, MSN = Mean shoot number, MSL = Mean shoot length, $\mathrm{MNN}=$ Mean node number.

Different degrees of morphogenetic response were observed in the presence of BAP and $\mathrm{Kn}$. Explants inoculated on BAP showed better response as compared to $\mathrm{Kn}$. The maximum FSI $(93.75 \%)$ was observed on BAP $(6.66 \mu \mathrm{M})$ supplemented medium (Table 1) contrary to the previous reports of Jahan et al. (2011) who reported low regeneration frequency on this concentration. Multiple shoots were also observed on different concentrations of BAP $(0.44,2.22,4.44$, $6.66,17.76,22.2 \mu \mathrm{M})$. Similar results were obtained by Siddique et al. (2006) while 
the contrary was reported by Rout et al. (2007). Maximum number of shoots $(14.13 \pm 0.999)$ was obtained on MS supplemented with BAP $22.2 \mu \mathrm{M}$ (Table 1, Fig. B). The maximum shoot length $(4.87 \pm 0.276)$ was obtained on $\mathrm{Kn}$ supplemented medium $(6.96 \mu \mathrm{M})$ (Fig. D) contrary to the previous reports by Rout et al. (2007).
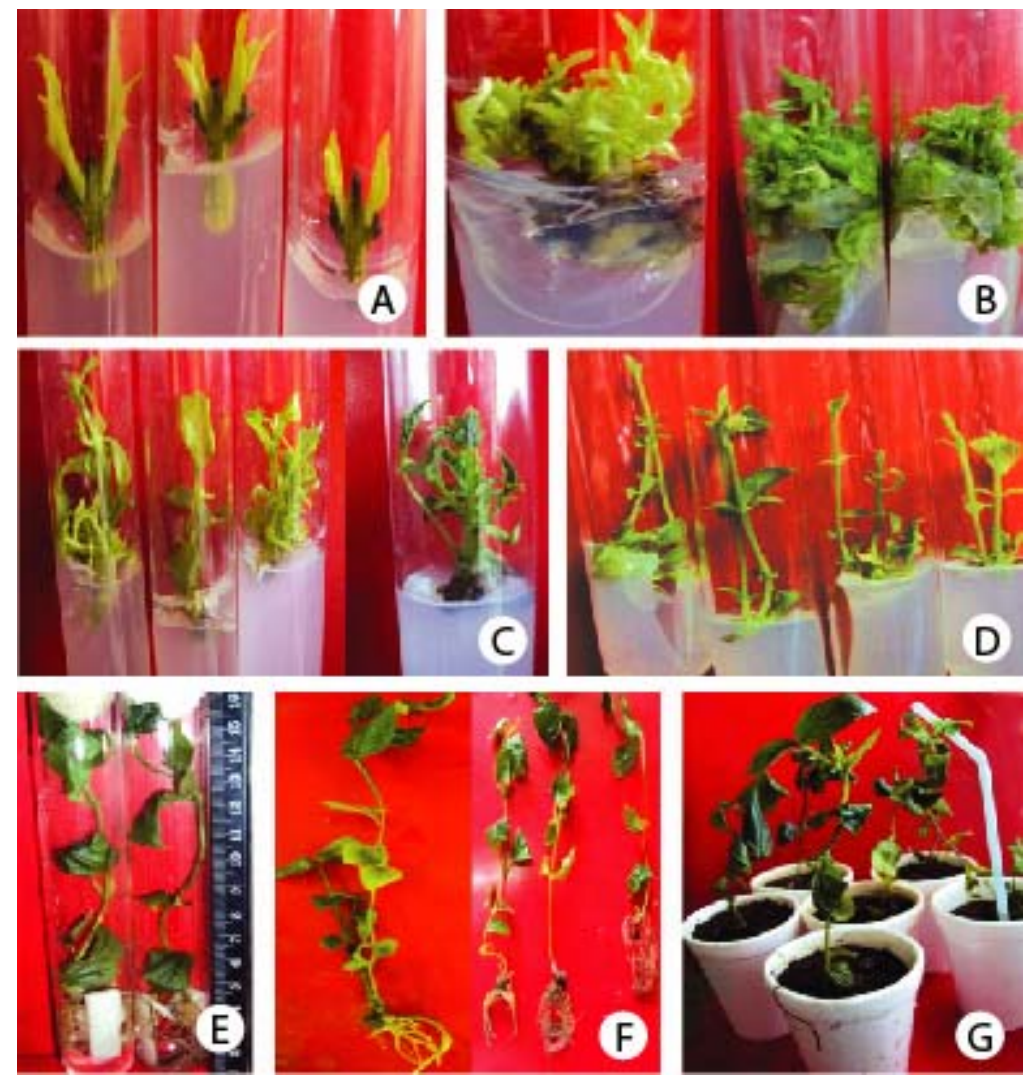

Fig. 1A-G: A. Shoot initiation on different concs. of PGRs, B. Multiple shooting on MS + BAP (22.2 $\mu \mathrm{M})$, C. Shoot elongation in BAP, D. Shoot elongation in Kn, E. Rooting of in vitro shoots, F and G. Hardening and acclimation of in vitro regenerated plants.

Rooting failed to occur on the full strength of MS (3\% sucrose) but half strength of MS with $2 \%$ sucrose was found suitable for root induction. Similar reports were observed by Rout et al. (2007). Individual shoots when inoculated in half strength of MS ( $2 \%$ sucrose) supplemented with auxins, enhanced the rate of rooting. The maximum frequency of root initiation (83.33\%) was obtained on half strength of MS ( $2 \%$ sucrose) in combination with NAA $(10.74 \mu \mathrm{M})$. Maximum mean root number $(13.2 \pm 1.8)$ was obtained on IBA $(9.86 \mu \mathrm{M})$ in combination with half strength of MS and $2 \%$ sucrose (Table 2, Fig. E). 
Efficient in vitro Regeneration of a Medicinal Plant

Table 2. Rooting from in vitro regenerated shoots of $N$. arbor-tristis (Values are Mean $\pm \mathrm{SE})$.

\begin{tabular}{lcccccc}
\hline PGR & Conc. $(\mu \mathrm{M})$ & MSL $(\mathrm{cm})$ & MNN & FRI $(\%)$ & MRN & MRL \\
\hline $1 / 2$ MS 2\% & - & $9.32 \pm 0.335$ & $7.26 \pm 0.266$ & - & - & - \\
$1 / 2$ MS 2\% & 0.49 & $8.91 \pm 0.746$ & $6.4 \pm 0.400$ & - & - & - \\
+ IBA & 9.86 & $11.91 \pm 0.400$ & $7.4 \pm 0.272$ & 33.33 & $13.2 \pm 1.826$ & $2.54 \pm 0.512$ \\
& 26.85 & $11.23 \pm 0.640$ & $7.8 \pm 0.261$ & 16.66 & $8.06 \pm 0.441$ & $4.92 \pm 1.097$ \\
$1 / 2$ MS 2\% & 0.57 & $9.94 \pm 0.601$ & $7.33 \pm 0.287$ & - & - & - \\
+ IAA & 11.4 & $12.89 \pm 0.733$ & $7.4 \pm 0.235$ & 33.33 & $6.26 \pm 0.602$ & $2.226 \pm 0.218$ \\
& 28.55 & $7.93 \pm 0.277$ & $6.06 \pm 0.206$ & - & - & - \\
$1 / 2$ MS 2\% & 0.53 & $7.85 \pm 0.408$ & $5.8 \pm 0.380$ & - & - & - \\
+ NAA & 10.74 & $10.36 \pm 0.532$ & $7.46 \pm 0.363$ & 83.33 & $6.93 \pm 0.402$ & $1.82 \pm 0.245$ \\
& 26.85 & $11.69 \pm 0.291$ & $6.06 \pm 0.206$ & - & - & - \\
\hline
\end{tabular}

FRI $=$ Frequency of root initiation, MSL $=$ Mean shoot length, $\mathrm{MNN}=$ Mean node number, $\mathrm{MRN}=$ Mean root number, MRL= Mean root length.

When shoots of the in vitro regenerated plantlets attained a height of 9-13 cm bearing healthy shoots and a good root system, the plants were subjected to hardening (Fig. F, G). They were subsequently transferred to poly cups containing presterile soil : sand : farmyard manure $(1: 1: 1)$ covered with perforated polythene. Finally the plantlets were transferred to field. Approximately $90 \%$ plantlets survived.

\section{Acknowledgement}

The authors gratefully acknowledge the financial support of the Madhya Pradesh Council of Science and Technology, Bhopal (M. P.), India.

\section{References}

Ahmed G, Roy P K and Mammu A N K (2001) High frequency shoots regeneration from nodal and shoot tip explants of Holarrhena antidysenterica L. Indian J. Exp. Biol. 39: 1322-1324.

Anonymous (1988) In: The wealth of India. A dictionary of Indian Raw material and Industrial products. Vol. VII, Publications and Information Directorate, CSIR, New Delhi, pp. 69-70.

Arulmozhi S and Sathiya N L (2007) Pharmacological activities of Alstonia scholaris Linn. (Apocynaceae) - A Review. Phamacognosy Rev. 1(1): 163-170.

Bhattacharya S, Das B, Ghose TK and Bhattacharya S (1999) Investigation of seed germination of Nyctanthes arbor-tristis (Oleaceae) in relation to the total phenol content. Seed Sci. Technol. 27: 321-327.

Jahan AA, Anis M and Aref IM (2011) Assessment of factors affecting acclimatization of Nyctanthes arbor-tristis L. Acta Biol. Hung. 62(1): 45-56. 
Karuppusamy S and Pullaiah T (2007) In vitro shoot multiplication of Bupleurum distichophyllum Wight. A native medicinal plant of Southern India. Plant Tiss. Cult. Biotech. 17(2): 115-124.

Khatune NA, Islam ME, Rahaman MAA, Mosaddik MA and Haque ME (2003) In vitro cytotoxic evaluation of new benzofuran derivative isolated from Nyctanthes arbortristis L. on Ehrilch Ascite Carcinoma Cells (EAC) in mice. Journ. Med. Sci. 3: 169-173.

Kirtikar KR and Basu BD (1993) Indian Medicinal Plants. 2nd ed., International Book Distributors, Rajpur Road, Dehra Dun, India.

Nair CKN and Mahanan N (2001) In: Medicinal plants of India, NAG Publication, Delhi, India. pp. 316-317.

Nair R, Kalariya T and Chanda S (2005) Antibacterial activity of some selected Indian Medicinal Flora. Turk. J. Bio. 29: 41-47.

Nawaz AHMM, Hossian M, Karim M, Khan M, Jahan R and Rahamatullah M (2009) An ethnobotanicals survey of Jessore district in Khulna Division, Bangladesh. AmEurasian J. Sustain. Agri. 3: 238-243.

Rahaman MM, Roy PK, Mannan MA and Roy SK (1999) Clonal propagation of Emblica officinalis through in vitro culture. Plant Cell Tiss. Org. 9: 17-22.

Rout GR, Mahato A and Senapati SK (2007) In vitro clonal propagation of Nyctanthes arbor-tristis Linn. - a medicinal tree. Hort. Sci. (Prague). 34(2): 84-89.

Roy SK, Roy PK, Rahaman M and Hossain (1995) Clonal propagation of Rouwolfia serpentina through in vitro culture. Acta Hortica. 390: 141-145.

Sasmal D, Das S and Basu SP (2007) Phytoconstituents and therapeutic potential of Nyctanthes arbor-tristis Linn. Phcog. Rev. 1: 344-349.

Seetharam YN, Barad A, Gururaj C, Joythishawaran G and Ghanti (2002) In vitro shoot regeneration from leaf and nodal explants of Enicostemma hyssopifolium (Wild) Verd. A vulnerable medicinal plant. Indian J. Biotechnol. 1:401-404.

Siddique I, Anis M and Jahan AA (2006) Rapid multiplication of Nyctanthes arbor-tristis L. through in vitro axillary shoot proliferation. World J. Agric. Sci. 2(2): 188-192.

Suresh V, Jnikumar S and Arunachalam G (2010) Antidiabetic activity of ethanolic extract of stem bark of Nyctanthes arbor-tristis Linn. Res. J. Pharm. Biol. Chem. Sci. 1: 311-317.

Talakal TS, Dwivedi SK and Sharma SR (2000) In vitro antitrypanosomal, potential of Nyctanthes arbor-tsristis leaves. Pharm. Biol. 38(5): 326-329.

Tuntiwachwuttiku P, Rayanil K and Taylor WC (2003) Chemical constituents from the flowers of Nyctanthes arbor-tristis. Sci. Asia. 29: 21-30.

Vats M, Sharma N and Sardana S (2009) Antimicrobial activity of stem bark extracts of Nyctanthes arbor tristis Linn. (Oleaceae). Int. J. Pharmacog. Phytochem. Res. 1:12-14. 